\title{
Analysis on National Strategic Planning and System Construction Under the Global Great Change
}

\author{
Jiahao Cai \\ School of International Studies, Jinan University, Guangzhou, China \\ Email address: \\ 474514345@qq.com \\ To cite this article: \\ Jiahao Cai. Analysis on National Strategic Planning and System Construction Under the Global Great Change. Journal of Political Science and \\ International Relations. Vol. 4, No. 2, 2021, pp. 66-71. doi: 10.11648/j.jpsir.20210402.16
}

Received: June 15, 2021; Accepted: June 24, 2021; Published: June 30, 2021

\begin{abstract}
If we want to say that human beings is in the global change, the author thinks the biggest variable in this big change is the technological revolution and some subsequent chain reactions, such as global industrial chain restructuring. At present, for a long time to come, although there will be many rich and rival multinational corporations to emerge in the world, the country is still an important actor in the world. Therefore, based on the country, it is very important to systematically analyze and explain the strategic direction of the national actors and its internal system construction. On the one hand, we should deal with the new industrial division of labor brought about by the technological reform, and on the other hand, we should properly solve the new problems emerging in the domestic society. In this context, this study hopes to provide some suggestions and suggestions for the strategic planning and institution-building of the most important actors in international relations today, namely the state. The author conducts research through historical document method and case analysis method, and sorts out some key cases in history and important laws in current international relations, thus forming important supporting materials for the conclusion of this study. The most important conclusions of this paper include two parts. The first part is that the complexity of national strategic planning is usually beyond a single dimension, which requires multiple considerations and a large amount of talent and energy. The second part is the national system construction, which can not be completely imported from outside, must be combined with their own national conditions and the actual continuous optimization and improvement, in order to maintain the matching of the system.
\end{abstract}

Keywords: Great Change, National Strategic, System

\section{Introduction}

Diplomacy among modern countries has been very frequent, and because of the many conventions formed in history, there are mostly rules to follow. Another phenomenon is that inter-state diplomacy, including bilateral and multilateral diplomacy, is highly standardized and procedural, with an inappropriate comparison, just like a product on the assembly line, and has a set of unified standards and specifications. Such diplomacy, often because the dialogue is too rigid and has fixed manuscripts, sometimes does not necessarily produce very specific results. As international activities become more and more abundant and become more and more complicated, the internal system construction of a country, as an actor, becomes more and more important. There are two main reasons: the system construction within the country guarantees the stability of the internal order of the country; On this basis, a country with stable internal order will be more motivated to act as a whole when it participates in international affairs, because it will have fewer internal disagreements.

The main purpose of this study is to find an effective model for strategic planning and institutional construction of state actors in the context of global great changes, so as to put forward some valuable opinions and suggestions. Due to the complexity of the current international environment and the sudden outbreak of COVID-19, the traditional mechanisms at home and abroad to deal with the real challenges are beginning to break down. Facts have proved that the unreasonable actions of many international actors have brought great losses to human society. It can be said that in today's society, a comprehensive analysis of how a country should act and restrain itself, has become a very urgent problem. 
This study focuses on solving two problems: one is how to formulate and construct the national strategic planning, and the other is what objective laws should be followed to formulate the internal system construction of a country. These two aspects form the solution to how state actors behave internally and externally. Of course, the main purpose of this study is to provide some valuable opinions and suggestions for reference.

\section{Diversified of International Environment and National Strategy}

\subsection{Complex Systems of Human Society}

\subsubsection{Trend Prediction and Assumption}

But in fact do not produce specific results, also does not mean meaningless. People who have a certain understanding of sociology should know that human society is an extremely complex system. Although each of us has to face this system every day, even under the research methods and research capabilities of human beings today, the complexity of the human social system is still unattainable. [1] The most important point is that a lot of research results in sociology, under the existing technical conditions, it is not falsified, a large number of research can only stay in the hypothesis and speculation stage, although a lot of speculation according to the existing knowledge, its accurate probability has been very high, such as mediocre persecution, a large amount of evidence is stored in the individual thinking, can not obtain, even obtained is not necessarily accurate, but according to common sense, people think that its probability is great.

\subsubsection{The Grasp of the Optimal Decision}

Therefore, in the human society, an extremely complex social system that we still cannot grasp, will there be a large number of accidents that cause great harm to the society as a whole. Small to the death of the family, to the destruction of the war. These things happen and progress is not even one person can control, the real conditions do not allow. [2] The uncertainty brought by complex systems to humans is too large that one has to look for a temporary optimal solution under existing conditions. This optimal solution seems to be that all people strengthen communication and cooperation to respond to systemic risks. Modern diplomacy is essentially an important means to deal with the systemic risks of society.

\subsubsection{A Massive Expansion of the Organization}

Many diplomatic mechanism of modern society is most traceable because of the outbreak of various risks in history, such as national meetings, negotiation and dialogue mechanism, largely because in history to cope with the risks of war, although now has entered the age of peace, but such a mechanism not only did not reduce but gradually increase, the reason will be explained. In some developed countries, there are still many international financial institutions with many functions, but mainly loans or assistance to regions in need. [3] Capital has brought great benefits to the development of human society, but its inevitable defect is the intermittent outbreak of systemic financial risks. The original intention of the establishment of international financial institutions is actually to deal with the frequent systemic financial risks.

\subsection{Organizational Culture and Structure}

\subsubsection{The Development of Technology and the Continuity of Civilization}

As mentioned just now, human beings are currently in an era of peace, and their understanding of finance is becoming more and more mature, so why do more and more bilateral and changeable foreign teacher activities between countries become more? This has to mention the important role of technological development and the continuity of civilization. [4] The development of technology does not just want to say that human abilities have become stronger and stronger by using tools, but with the birth of some weapons of destruction.

\subsubsection{Positive Feedback Effect of Technological Development and Coping Mechanism}

From the earliest artillery machine gun, to the later atomic bomb, to today's artificial intelligence, human flesh has become more and more vulnerable, although from the end of the second world war, human generally maintained nearly eighty years of peace, but in the strong technical background, and international relations is essentially a kind of jungle relationship, leading to human almost always worry in the next moment can instantly, inner fear forced human to develop a lot of dialogue mechanism to deal with possible systemic risk at any time. [5]

\subsubsection{Case Study: The Continuity of Chinese Ancient System}

The other thing is that the continuity of civilization is very important. It can be said that as long as mankind still exists, the savage side of its human nature will never die. In history, most of the regions were once trapped in the closed-loop quagmire of barbarism of civilization, that is to say, with the rise of a regional empire, a civilization could flourish, but with the collapse of the empire, mankind returned to barbarism, and the fire of civilization went on fire. The author mentioned in another article, the Chinese civilization is the longest lasting civilization in human history, because civilization continues, because "hundred generations line Qin regime", so the Chinese people can learn a lot of lessons from history, such as not unnecessary expansion of their unbearable territory, profound lessons in history. One of the most mainstream modern civilizations in the world today. [6] Although the major civilizations around the world participate in its development process, its backbone is still the vein of western civilization. If we do not look at the interruption in the middle of it, its origin is no less than the Chinese civilization. Modern technology has greatly strengthened the ability to store information. 
The connection between The Times and The Times has never been so close, and human beings's historical vision has become clearer and clearer. No one can turn a blind eye to the painful historical lessons.

\subsection{The Institutionalization and Diversification of International Exchanges}

\subsubsection{Highly Ritualized Diplomacy}

So, both out of emotion and reason, humans today have reason to develop diplomatic mechanisms that bring more certainty to themselves, even if sometimes it doesn't solve any specific problems. Modern diplomatic activities are not only increasing in number, but also increasingly specialized in size. If pay attention to some multilateral diplomatic process, it is not difficult to find these activities show a highly modal situation, such as a multilateral diplomatic activity often conducted in several days, must first have a full assembly, generally led by the organizer, then a round table, country leaders around a table, a stiff set of prepared manuscripts; [7] Finally, some bilateral dialogue in the gap of the activities, dialogue process is arranged early, generally not many surprises. There may be doubts about the actual benefits of such a mechanized form of activity.

\subsubsection{Stability and Efficiency are The Characteristics of the Mechanism}

The author can comb such a situation to a certain extent. The deliberations of the highest standard international conferences are extremely large, the first with many matters involved, and the second with complex matters, even time bombs. Most of the frequency of international high-level meetings is not high, although the total number is large, but for a specific meeting, often a year or a year, such frequency to deal with changeable international affairs is often a drop in the bucket, although set up some permanent institutions, but they during the recess to implement the meeting or prepare for the next meeting itself needs a large number of managers, any personnel setting will be likely to reduce the cost. [8] So it seems that a lot of work must be done during the meeting, which means that the conference should be both efficient and rich. Then every word in each speech must be considered repeatedly, and here we can imagine that although the parties appear in personal form, there must be a strong team operating behind it, otherwise it cannot be both efficient and rich.

\subsubsection{Approach International Affairs from a Whole-process and Multi-level Perspective}

Here it also comes to the various events and states occurring in the real world that are three-dimensional, or even multi-dimensional, at least the four-dimensional phenomenon of increasing time on the basis of three-dimensional stereo. Our human brain and memory is about four dimensions, but unfortunately, once people change their thoughts into words, words have basically become a two-dimensional line, through the accumulation of words can be roughly reduced to three dimensions. [9] If you want to restore a thinking of such a three-dimensional expression, it must need a rich imagination.

\section{Thoughts on the Legalization Path of China in the 21st Century}

\subsection{The Basic Role of the Constitution}

The Chinese people in the 21 st century have a relatively comprehensive understanding of the Constitution of a country. There is a saying that the Chinese people should be familiar with it, that is, "the Constitution is the fundamental law of the country", which shows the importance of the Constitution. But here to say is that the value of the Constitution is absolutely not only reflected in the constant provisions, he is actually everywhere in our lives. Anyone who has seen the Constitution of our country should know that the Constitution is not much, a thin pamphlet. Although we ordinary people are enjoying the benefits of the Constitution all the time, an ordinary person is basically less likely to violate the regulations of the Constitution, not even the access to the Constitution. Here, referring to the most essential role of the constitution, that is to restrain government power. If the role of the constitution is to restrain government power, it is very important how to restrain such a strong secular power with the words in such a thin pamphlet. [10]

\subsection{Different Ways to Constrain Power}

\subsubsection{The Restraint of Power Through Violence}

In fact, there were many ways to restrain secular power in history. Although ancient China was the dominant imperial power, even the emperor could not act recklessly. People often joke that ancient China also had an election system, but the interval of each election is too long, and the election cost is too much, often killing many people, such an election is a change of dynasty. In fact, the rise and fall of the past dynasties is also very regular to follow, often the incompetence of the end of the emperor, and then the people died, the people uncovered and opened a new dynasty. After the dynasty, followed by the economy gradually recovered, the national population increased, the dynasty gradually reached its peak, but due to the population and resources reached the limit, the gap began to gradually widen, the rich tax evasion, national fiscal turn, civil unrest, in addition to the founding emperor are grown in the deep palace, faint, and finally the people started to complete a new round of "election". Such "elections" were generally very bloody. [11] Wang Mang's usurpation of Han was also the strong support of the people at the bottom level, but eventually led to the disaster of the reduction of the national population by half, which could not make people sigh.

\subsubsection{Discussion of the State Governance in Today's World}

There are also more moderate ways to restrict power in Chinese history. For example, the relationship between the monarch and ministers, in history, like Emperor Taizong 
and Wei Zheng, an open mind and a story who dare to speak bluntly are often spread by later generations. Another is the Chinese people have believed in destiny such a concept, the emperor power, powerful, but he had to obey the destiny, Chinese history often explain some unknown, cannot understand the phenomenon into auspicious, of course, some people deliberately create some "auspicious" to coax the emperor happy or restrain the emperor's behavior, it is such an idea has a great limit for the emperor. It is also the most important, that is, the traditional Chinese Confucian concept of Confucianism. Confucianism is the background color of Chinese civilization. It has lasted for thousands of years since its establishment, and still affects every Chinese person today. Many Analects of Confucius are still of infinite value today. Confucianism is also one of the important blueprint of the Chinese imperial examination, he restrained the ancient Chinese intellectuals, there is no lack of famous officials, their golden words have played a great role on generation of emperor, their deeds have been celebrated to today, such as "rui scold the emperor". Confucian culture, as the underlying gene of a civilization, was a normative regulation for all Chinese people, including the emperor. [12]

\subsection{Strategies for Running a Mature Society}

\subsubsection{Case: Three Regime Changes in Ancient China}

But those familiar with modern politics should not be difficult to understand that the restraint of the bottom people on government power actually cannot be endless. Here can also some examples of China. For example, the above mentioned Wang Mang usurp Han, Wang Mang usurp is actually completely different from any other usurpation in Chinese history, to know that the minister usurpation is not by insidious and intrigue, even if a person can usurp the throne, can not to everyone admit is also a big problem. [13] Zhu Di, ancestor of the Ming Dynasty, is a typical example. Zhu $\mathrm{Di}$ is only a mutual usurpation between brothers, whose difficulty has been very difficult. A large number of opposition has been connected by nine families, and the maintenance of its regime must be completed through a large number of homicide. And for the later Ming Dynasty Jin Yi Wei and eunuchs flood, Zhu Di has the main responsibility. [14] The process of usurpation between brothers has been so complicated, not to mention the foreign minister, so Wang Mang's legitimacy does not simply come from his resourcefulness, but he must have satisfied all the imagination of the people of that era for an excellent emperor. Wang Mang himself is a great scholar who read poetry and books. He greatly abided by the Three Gang and Five Principles and is a very self-disciplined person. It can be said that the character he held before usurping the throne actually moved the whole world, and the support at the bottom achieved him. Therefore, after he became emperor, he must respond to the sufferings of the people, engage in "welfare policies", and devote all the preferential measures to the people, because such drastic reform had shaken the four beams and eight pillars of the empire, and finally made the people die, and a large number of people died of fate. Another example is the constitution of the late Qing Dynasty. In fact, it seems today to us that the rulers of the late Qing Dynasty did not vigorously promote the reform. Under the leadership of reformers such as Empress Dowager Cixi, Prince Gong, and Prince alcohol, the economy of the late Qing Dynasty once showed a growth trend, and the process of constitutionalization was also in full swing. In the last 30 years of the 19th century, once created a light Zhongxing era, until the Empress Dowager Cixi and the death of Emperor Guangxu emperor Puyi ascended the throne, the actual helmsman carrying Feng is still a firm reform, promised to establish the original constitutional date unchanged. However, at this time, the folk petitions came in an endless stream, forcing the court to shorten the constitutional time of the petition scale was bigger and bigger, and even some young people sacrificed their lives, causing public opinion to force the court. Of course, the helm of the last generation of the imperial court no longer had the ability to control such a situation. The flood of history can only roll forward, and the examination paper of The Times will continue to wait for the next "examinee" to write.

\subsubsection{Discuss the State Governance in Today's World}

This is the experience and lesson in Chinese history. Therefore, the widely transmitted contemporary democratic power as the most important constraint of government power is actually very necessary for dialectical thinking. This is easily reminiscent of the populist trend in many regions in recent years. We Chinese often say that the masters are among the people, but the folk masters are often full of ways, each showing their talents. There is no lack of professional talents among the people, but this talent is not another talent, and not everyone needs the professional ability needed for national governance. [15] What's more, the general public is more ordinary people, and the discussion of national affairs can only stay to a very superficial extent, so the democratic society may first have to be a mature society.

\subsection{Institutional Construction Needs Strategic Determination}

Conaining government power is a technical job, and many times a very delicate balance. [16] The constraints on rights must be a dynamic and sometimes rebound, so key individuals play a huge role in it. Many of the articles in the Constitution are only the presentation of various complex phenomena in the real world contained behind it. Such presentation is certainly not unchanged, and can also be changed after certain procedures, and it is not necessary for each country to copy the Constitution of developed countries according to its own national conditions. Today's countries in Africa copy the American constitution, but it is true that the country will not become beautiful immediately since because of an excellent written constitution. 


\section{Conclusions}

General Secretary Xi Jinping once said that the world today is undergoing profound changes unseen in a century. In the face of the profound fusion of the international community, every country hopes to cope with the complex international environment by making longer term strategic plans. At the same time, each country also hopes to carry on the transformation to its own country through its own system design, in order to seek more rapid and steady development. The key of this study is to analyze the better model of the country's own development and external communication based on the rapidly changing international situation.

For major events such as international affairs, we should not be careless. We should always sort out and understand the heavy desk work after the end of relevant diplomatic activities. Here, the author believes that everyone should have a cautious and understanding of the complex phenomena in the rapid change. The constitutional process of China was also arduous and arduous. That is to say, when a country participates in foreign affairs as a unit, it is necessary to simplify the complex practical problems to operational concrete action plans, which requires the participation of a large number of professionals. Moreover, for many complex international events, it also requires all people to have a higher understanding ability and provide support.

As for the system construction within a country, this study mainly combs and analyzes the important cases in Chinese history. It was not until the written Constitution established by our country after the founding of the People's Republic of China was upheld for a long time. However, the constitutional penetration rate of ordinary Chinese people is not high. It can be said that our country has a road to overcome many difficulties. Looking at other countries in the world, no country can completely copy the existing experience of other countries to achieve system construction without going through some hard practice. Therefore, system construction not only needs delicate design, but also needs constant adjustment and modification in the process of practice, in order to maintain vitality.

\section{References}

[1] Antonio Alejo, \& Rebecka Villanueva Ulfgard. (2019). Proactive, Responsible, and in Good Faith: Network Diplomacy in Mexico's Ministry of Foreign Affairs. Latin American Policy, 10 (2), 220-235.

[2] Witkowski Tadeusz, Antczak Arkadiusz, \& Antczak Pawel. (2011). THE EFFECTIVENESS OF NEIGHBORHOOD STRUCTURES IN LOCAL SEARCH ALGORITHMS FOR FLEXIBLE JOB SHOP SCHEDULING PROBLEM. Proceedings of 2011 International Conference on Mechanical Engineering and Technology, November, 24-25.

[3] Peter Richter. (2017). Trade Promotion in Nepal. Foreign Trade Review, 52 (1), 48-59.

[4] Fumei XU. (2018). Research on the FunctResearch on the Function of Science and Technology Culture in the
Construction of Ecological Civilizationion of Science and Technology Culture in the Construction of Ecological Civilization. Cross-Cultural Communication, 14 (2), 36-40.

[5] Li Qiaohua, \& Bai Yilu. (2020). The Dynamic Mechanism and Realization Paths for High-quality Development of Manufacturing Enterprises in the New Era. Contemporary Social Sciences, (3), 59-75.

[6] GAO Xing, ZHANG XiaoLing, YANG DongYa, SHEN Chen, \& WU XinZhi. (2010). Revisiting the origin of modern humans in China and its implications for global human evolution. Science China (Earth Sciences), 53 (12), 1927-1940.

[7] Hotez Peter J, \& Narayan K M Venkat. (2021). Restoring Vaccine Diplomacy. JAMA: The Journal of the American Medical Association, 325 (17), E1-E2.

[8] N Larionova, J Varlamova, D Rakhmatullina, \& L Zulfakarova. (2018). How the institutional environment affects the banking sector: evidence from BRICS. Journal of Physics: Conference Series, 1141 (1), 1-7.

[9] Xiaohu YOU, Cheng-Xiang WANG, Jie HUANG, Xiqi GAO, Zaichen ZHANG, Mao WANG, Yongming HUANG, Chuan ZHANG, Yanxiang JIANG, Jiaheng WANG, Min ZHU, Bin SHENG, Dongming WANG, Zhiwen PAN, Pengcheng ZHU, Yang YANG, Zening LIU, Ping ZHANG, Xiaofeng TAO, Shaoqian LI, Zhi CHEN, Xinying MA, Chih-Lin I, Shuangfeng HAN, Ke LI, Chengkang PAN, Zhimin ZHENG, Lajos HANZO, Xuemin (Sherman) SHEN, Yingjie Jay GUO, Zhiguo DING, Harald HAAS, Wen TONG, Peiying ZHU, Ganghua YANG, Jun WANG, Erik G. LARSSON, Hien Quoc NGO, Wei HONG, Haiming WANG, Debin HOU, Jixin CHEN, Zhe CHEN, Zhangcheng HAO, Geoffrey Ye LI, Rahim TAFAZOLLI, Yue GAO, H. Vincent POOR, Gerhard P. FETTWEIS, \& Ying-Chang LIANG. (2021). Towards 6G wireless communication networks: vision, enabling technologies, and new paradigm shifts. Science China (Information Sciences), 64 (1), 1-74.

[10] Christoph J. Von Bismarck, Swetlana L., \& Partsch. (1992). Revolution and continuity: Constitutional developments in the five new states of the Federal Republic of Germany and their influence on the amendment of the Constitution of the Federal Republic, the Basic Law. Comparative and International Law Journal of Southern Africa, 25 (2), 156-180.

[11] Mark Doyle. (2011). Massacre by the Book: Amritsar and the Rules of Public-Order Policing in Britain and India. Britain and the World, 4 (2), 247-268.

[12] Lubkemann, Isser, \& Chapman. (2011). Neither State Nor Custom - Just Naked Power: The Consequences of Ideals-Oriented Rule of Law Policy-Making in Liberia. The Journal of Legal Pluralism and Unofficial Law, 43 (63), 73-109.

[13] Chauncey S. Goodrich, \& Professor Dub. (1959). Professor Dubs' Translation of the Biography of Wang Mang. Journal of the American Oriental Society, 79 (2), 104-123.

[14] Chao Rui. (2020). Language Policies Under Zhu Yuanzhang and Zhu Di Regimes: A Comparative Perspective. International Journal of Language and Linguistics, 8 (3), 108-114. 
[15] Juan Carlos Martínez. (2020). Anthropological Expert Work in Today's Legal Field: Between Legitimizing the State Judicial Arena and Seeking Justice for Indigenous Peoples. American Anthropologist, 122 (3), 632-638.
[16] Shi Weiliang, Eric Huybrechts, Yin Zhi, Simon Teyssou, Zheng Xiaojin, Laurent Coudroy de Lille, Wu Tinghai, Olivier Chadoin, Li Min, \& Qian Fang. (2020). Sino-French Seminar of Meeting the New Challenges of Territorial and City Planning. China City Planning Review, 29 (2), 6-23. 